\title{
Responses of substantia gelatinosa neurons to putative neurotransmitters in an in vitro preparation of the adult rat spinal cord ${ }^{\star}$
}

\author{
W. ZIEGLGÄNSBERGER and B. SUTOR \\ Max Planck Institute for Psychiatry, Department of Neuropharmacology, Kraepelinstr. 2, 8000 Munich 40 (F.R.G.)
}

(Accepted July 26th, 1983)

\begin{abstract}
Key words: substantia gelatinosa - single unit recording - adult rat spinal cord in vitro -
\end{abstract} microiontophoresis - amino acid neurotransmitters - opioid peptides

\begin{abstract}
Extracellular recordings were performed from neurons of the substantia gelatinosa (SG) in an in vitro preparation obtained from the spinal cord of adult rats. About $40 \%$ of neurons were spontaneously active. They could be synaptically influenced by low and high threshold fiber input entering the spinal cord through dorsal and ventral roots. Repetitive low threshold stimulation led to a transient increase in activity of a number of these neurons, whereas high intensity stimulation predominantly reduced excitability. The majority of non-spontaneously active neurons responded to an increase of stimulus intensity covariantly with an increase in firing rate. The excitatory effect of phoretically administered L-glutamate as well as synaptically induced and spontaneous activity was reduced or abolished by phoretically administered GABA, glycine or the enkephalin-analogue D-Ala ${ }^{2}$-D-Leu ${ }^{5}$-enkephalin. The actions of the enkephalin analogue were blocked by phoretically applied naloxone. The findings are consistent with the notion from in vivo investigations of a structurally and functionally heterogeneous population of neurons which display a responsiveness to microtopically applied putative neurotransmitters resembling dorsal horn neurons in deeper layers.
\end{abstract}

The dense axonal and dendritic arborization and the small size of cell bodies of the substantia gelatinosa (SG) have impeded extensive electrophysiological analysis of this site until recently1-3,10,12,15-17,20,24, for review see ${ }^{5,23}$. From those studies as yet undertaken, certain common features emerge: most cells in the SG are influenced by cutaneous afferents, including C-fibers, triggering complex tonic and phasic excitatory/inhibitory interactions. Very little is known about the descending influences affecting their discharge activity ${ }^{4}$. Since most of the recently characterized neuropeptides have been found preferentially in cell bodies and terminals of the SG (for review see refs. 13 and 14) peptidergic, in particular endorphinergic, mechanisms have been implicated in the control of SG neurons over cells giving rise to spino-fugal systems (see refs. 27).

The present study shows that in vitro recordings can be obtained from spinal cord slices of adult rats in which the profuse interconnections between SG cells and their connections with other neurons of the dorsal horn are fully developed. Male rats (Wistar,
180-200 g) were anesthetized with urethane (1.3 $\mathrm{g} / \mathrm{kg}$, i.p.). A laminectomy was performed from sacral (S1) to low thoracic segments (T 10/11). The dura was dissected and the spinal cord was removed with about $0.5 \mathrm{~cm}$ of the attached dorsal and ventral roots. The tissue was transferred to oxygenated artificial CSF (mM): $\mathrm{NaCl} 124 ; \mathrm{KCl} 5.0 ; \mathrm{NaH}_{2} \mathrm{PO}_{4}$ 1.25; $\mathrm{CaCl}_{2} 2.0 ; \mathrm{MgSO}_{4} 2.0 ;$ Glucose $10.0 ; \mathrm{NaHCO}_{3} 26$; saturated with $95 \% \mathrm{O}_{2}$ and $5 \% \mathrm{CO}_{2}, \mathrm{pH} 7.3-7.5$ at $4{ }^{\circ} \mathrm{C}$ and rinsed for $30 \mathrm{~s}$. Six to 8 transverse slices (400-600 $\mu \mathrm{m}$ thick) were then cut from lumbar segments 8.9 with a tissue chopper and placed in the recording chamber and perfused with warm $\left(35^{\circ} \mathrm{C}\right)$ oxygenated artificial CSF (flow rate: $1-2 \mathrm{ml} / \mathrm{min}$ ). The dorsal and ventral roots were placed on bipolar stimulating electrodes. Recording was commenced after $1 \mathrm{~h}$ of incubation. Both, recording and application electrodes were aimed at the clearly visible translucent band in the dorsal horn corresponding to lamina $^{2}$.

For recording the electrodes were filled with a mixture of $1.6 \mathrm{M}$ potassium-citrate and $1.0 \mathrm{M} \mathrm{KCl}(10: 1)$

\footnotetext{
* A preliminary report was presented at the Joint Meeting of the German Physiological and Pharmacological Societies.
} 
or with $0.2 \mathrm{M} \mathrm{KCl}$ in $0.05 \mathrm{M}$ potassium-phosphatebuffer at pH 6.2 (ohmic resistances, 60-90 M $\Omega$; tip size, $<1 \mu \mathrm{m})$. The electrode assemblies consisted of a 4-barrelled micropipette (overall tip diameter 4-5 $\mu \mathrm{m})$ containing fiber inserts for rapid filling. The multibarrelled electrode was glued in parallel with the recording electrode at a horizontal distance of 30-100 $\mu \mathrm{m}$. Solutions used for phoretic administration were: L-glutamate (GLU), $0.5 \mathrm{M}, \mathrm{pH} 8.0 ; \gamma$-amino-butyric acid (GABA), $0.5 \mathrm{M}, \mathrm{pH} 4.0$; D-Ala²-D-Leu5-enkephalin (DADL), $0.1 \mathrm{mM}, \mathrm{pH}$ 5.0; naloxone, 0.1 $\mathrm{mM}, \mathrm{pH}$ 5.0. Except for GLU, all compounds were administered as cations. Current neutralization was routinely employed. Backing currents of 10-20 nA were used. The neuronal activity was fed into a voltage-gating device, integrated ( $1 \mathrm{~s})$ and either dis- played on a chartwriter or the unit spike was used to modulate the $\mathrm{z}$-axis of the oscilloscope (dot-display). Stimulus intensities $(0.1-100 \mu \mathrm{A})$ are given in multiples of threshold. Stimulus duration varied from 0.05 to $0.5 \mathrm{~ms}$ and stimulus frequency between 0.5 to $1 \mathrm{~s}^{-1}$.

Stable extracellular recordings of up to several hours in duration, were obtained from 120 SG units preferentially located in the dorsal half of the translucent zone (corresponding to lamina 2). Small movements of the manipulator dramatically lowered spike size suggesting recordings from small neuronal elements. The recorded action potentials displayed amplitudes in the range of $1-20 \mathrm{mV}$ and duration of 1.2-2.0 ms. To exclude recordings from axons or primary afferents only units responding to phoretically

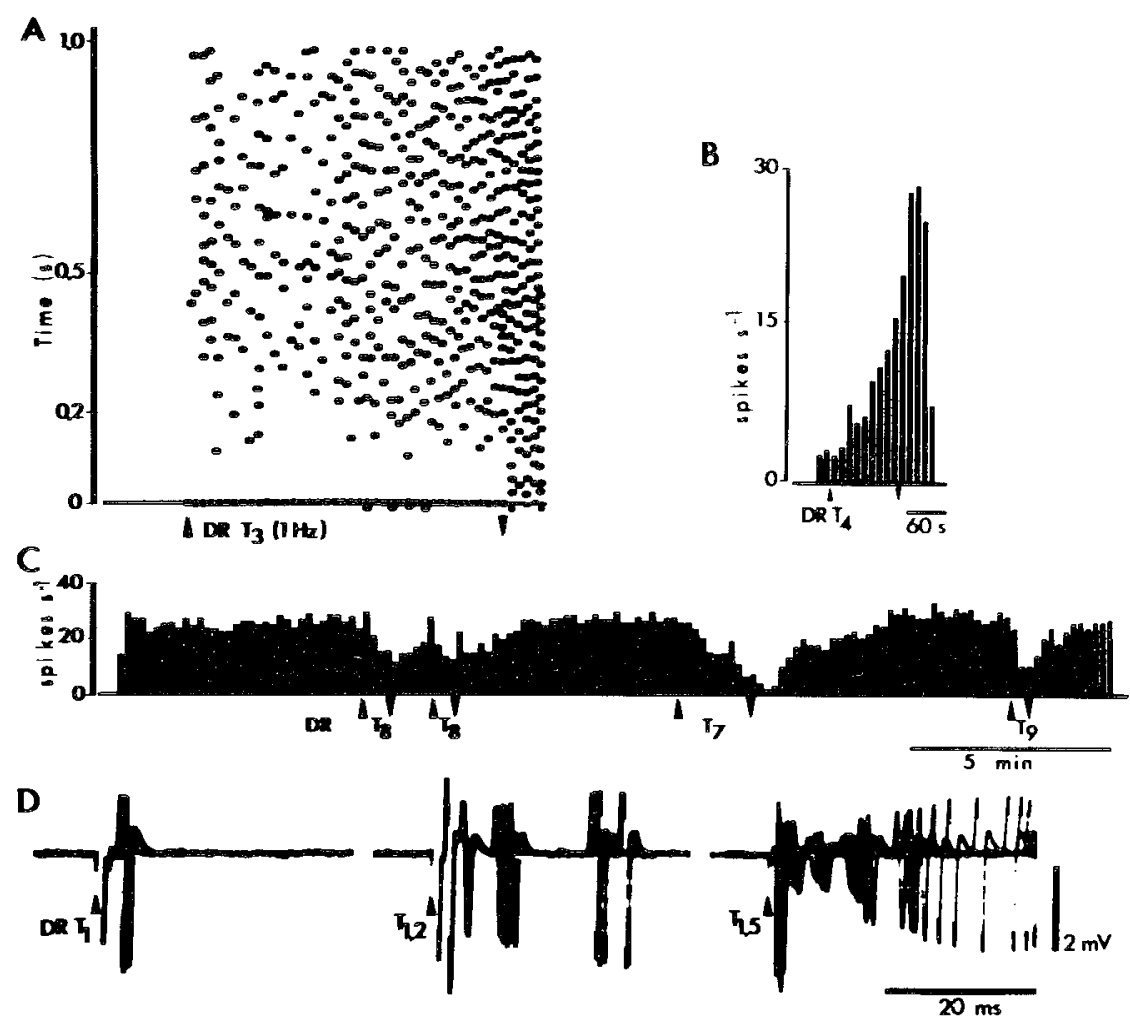

Fig. 1. Responses of SG neurons to dorsal root stimulation. A: dot-display of a 'wind-up' in a non-spontaneously active neuron following dorsal root stimulation $\left(1 \mathrm{~s}^{-1}\right)$ at 3 times threshold intensity (DR $\mathrm{T}_{3}$; pulse duration $0.05 \mathrm{~ms}$ ) the 'wind-up' occurred within $0.5 \mathrm{~min}$. Note, decrease in response latency with ongoing stimulation. The neuron remained spontaneously active after termination of stimulation. B: 'wind-up' of a spontaneously active neuron during dorsal root stimulation $\left(0.5 \mathrm{~s}^{-1}\right)$ at 4 times threshold intensity $\left(D R \mathrm{~T}_{4}\right.$; pulse duration $0.05 \mathrm{~ms}$ ). Continuous ratemeter recording integration times $10 \mathrm{~s}$. Note that the 'build-up' of activity did not end with stimulation. C: depression of a spontaneously active neuron by dorsal root stimulation $\left(0.5 \mathrm{~s}^{-1}\right)$ at $7-9$ times threshold intensity $\left(D R T_{7}, T_{8}, T_{9}\right.$; pulse duration $0.05 \mathrm{~ms}$ ). Continuous ratemeter recording (integration time $1 \mathrm{~s}$ ). D: extracellular (AC-coupled) recordings of a nonspontaneously active neuron at 3 different stimulus intensities (DR $T_{1}, T_{1.2}, T_{1.5}$ pulse duration 0.05 ms; 5 traces superimposed). Increase of stimulus intensity led to an increase in discharge frequency. The latency of the first spike decreased, whereas its amplitude increased. At the same time the amplitude of the spikes immediately following the first one (elicited on top of the EPSP) was reduced. 
administered GLU were sampled. Recordings from dendrites of deeper cells penetrating into these laminae are rather unlikely since they are most probably too small when they branch in the recording area. Also the shape of the action potentials indicated recordings from primarily somatic sites. Clear postsynaptic potentials recorded after successful intracellular impalements following the extracellular analysis also support the notion of a somatic recording site. Occasional recording from ectopically situated neurons of the marginal layer cannot be excluded although the electrodes were always clearly aimed at regions below the marginal zone.

Prior to drug application, all neurons were tested for their responsiveness to dorsal and ventral root stimulation. Forty-eight (40\%) of the neurons recorded were spontaneously active (firing rate: $5-15 / \mathrm{s}$ ). They could all be synaptically influenced by dorsal root stimulation (DR). In $60 \%$ of cases repetitive stimulation with low intensities (2-4 times threshold) led to a progressive increase in the response ('wind up') (Fig. 1A, B). This 'wind-up' phenomenon developed within $0.5-10 \mathrm{~min}$ of stimulation and lasted in some neurons up to $30 \mathrm{~min}$. High intensity stimulation (7-10 times threshold) caused a progressively increasing inhibition in 21 out of 48 neurons tested (Fig, 1C). After a resetting of the stimulus to threshold intensities the response was found to be reduced or abolished for up to $20 \mathrm{~min}$. This inhibitory action of high intensity dorsal root stimulation could be reduced or blocked by bicuculline methochloride $(2 \mu \mathrm{M})$ added to the perfusion medium in 4 out of 5 cells tested. Ten cells out of 26 responded to ventral root stimulation at high intensities. Two cells in this sample were inhibited whereas 8 were activated. In the non-spontaneously discharging neurons the stimulus response consisted out of $2-5$ spikes at threshold and increased monotonously with stimulus intensity. The latency of the first spike shifted towards shorter latencies. At higher stimulus intensities (2-3 times threshold) the action potentials (except for the first) immediately following the stimulus, were reduced in amplitude (Fig. 1D). Several neurons $(n=6)$ showed 'wind-up' and two of these cells remained spontaneously active after termination of the stimulation for the entire recording period $(2 \mathrm{~h})$.

Iontophoretic application of GLU with short pulses $(10-150 \mathrm{nA} / 10-20 \mathrm{~s})$ caused excitation after differing delays (500 $\mathrm{ms}$ to $15 \mathrm{~s}$ ) depending from the electrode configuration (horizontal tip separations: $30-100 \mu \mathrm{m}$ ) and the phoretic currents employed. The excitatory action was commonly reversible in 1-3 s and was followed by a decreased excitability, probably due to the hyperpolarization entailing GLU administration $^{28}$ (see Fig. 2A). The spontaneous and/or induced neuronal activity of all cells encountered were inhibited by phoretically administered GABA (10-100 nA) (Fig. 2B) and glycine (5-80 nA) within 1-10 s. The action was reversible within $2-8 \mathrm{~s}$ depending on the duration of application and the phoretic currents employed. Application of the enzymatically stable enkephalin-analogue D-Ala²-DLeus-enkephalin (DADL, $\delta$-receptor preferring agonist) at a dose range of 20-140 nA caused within

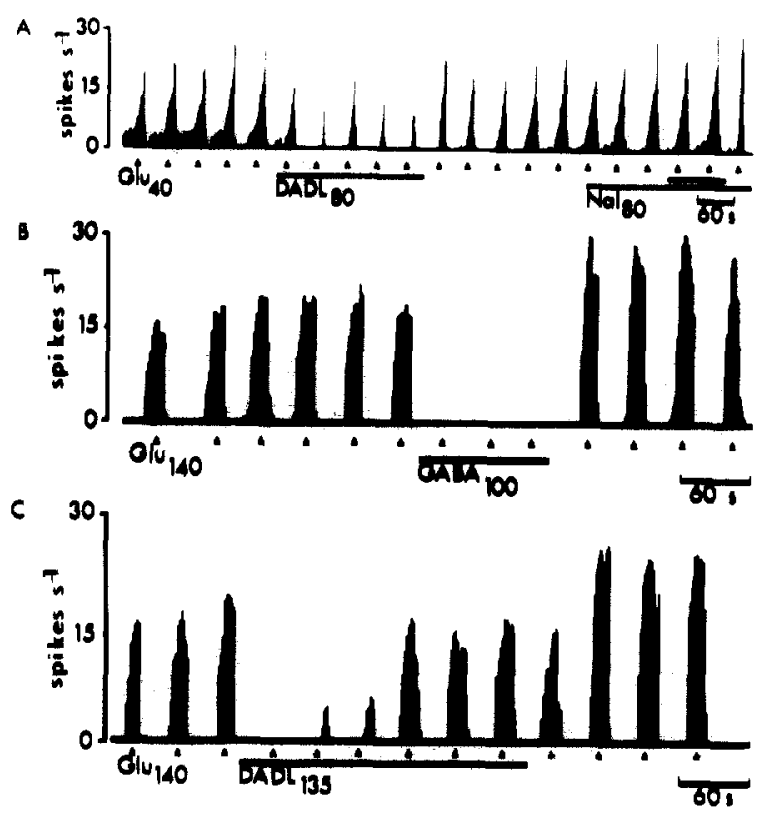

Fig. 2. Responses of SG neurons to microiontophoretically applied putative neurotransmitters. A: ratemeter recording (integration rate $1 / \mathrm{s})$. Inhibitory action of DADL $(80 \mathrm{nA})$ on spontaneous and GLU-evoked activity $(40 \mathrm{nA} / 20 \mathrm{~s})$. Naloxone $(\mathrm{Nal}, 80 \mathrm{nA}$ ) antagonized the depressant effect of DADL. Note, the postexcitatory depression after applications of GLU. In this and the following traces the recordings are continuous; drug applications are indicated by horizontal bars, except GLU (black triangles); ejection currents (subscripts) are given in nA. $B$ : ratemeter recording (integration rate $1 \mathrm{~s}$ ). Depressant effect of GABA (100 nA) on GLU (140 nA/20 s) discharge activity. $C$ : ratemeter recording (integration rate $1 \mathrm{~s}$ ). Development of acute tolerance during prolonged application of DADL (135 $\mathrm{nA}$ ). The non-spontaneously active neuron was driven by brief application of GLU (140 nA, $20 \mathrm{~s})$. The inhibitory action of DADL decreased and almost reached control levels despite continuous application (see also refs. 11 and 25) 
$10-30 \mathrm{~s}$ a depression (50\% reduction of discharge activity) of spontaneous (10 out of 12) and/or GLU-induced activity (12 out of 15) (Fig. 1A). After termination of application the inhibitory effect persisted for $0.5-5 \mathrm{~min}$. The inhibitory action of DADL was antagonized by phoretically applied naloxone (50-100 $\mathrm{nA} / 1-2 \mathrm{~min}$ ) (Fig. 2A). Naloxone alone caused a slight increase in firing rate in several neurons. Prolonged application of opioid peptides was associated with a progressive decrease in the inhibitory action (Fig. 2C). The neurons $(n=3)$ reached control level firing rates within 5-30 min despite ongoing application and transiently increased their firing rate above control levels after termination of application (see refs. 11 and 25) indicating the development of acute tolerance and dependence on these cells.

The present in vitro investigations are in agreement with previous in vivo studies which suggest that most SG cells are under the influence of afferent inputs, some of which exert opposite functional effects, carried in large and small diameter fibers (for review see ref. 5). Since descending influences are effectively interrupted the observed transient changes of neuronal excitability following repetitive afferent stimulation which are also seen in vivo $^{24}$ have to be explained by segmental mechanisms. The bicuculline-sensitive inhibition induced by dorsal root (in a few neurons, also ventral root) high intensity stimulation suggests a GABAergic (pre- and/or postsynaptic) link in this segmental circuitry. All the afferents to SG entering the spinal cord through the ventral root were high threshold fi-

1 Bennett, G. J. and Hayashi, H., Abdelmoumene, M. and Dubner, R., Physiological properties of stalked cells of the substantia gelatinosa intracellularly stained with horseradish peroxidase, Brain Research, 164 (1979) 285-289.

2 Cervero, F., Iggo, R. and Molony, V., Activity from single neurones recorded in gelatinosa Rolandi of the cat, J. Physiol. (Lond.), 269 (1977) 35-36P.

3 Cervero, F., Molony, V. and Iggo, A., Extracellular and intracellular recordings from neurones in the substantia gelatinosa Rolandi, Brain Research, 136 (1977b) 565-569.

4 Cervero, F., Molony, V. and Iggo, A., Supraspinal linkage of substantia gelatinosa neurones: effects of descending impulses. Brain Research, 175 (1979) 351-355.

5 Cervero, F. and Iggo, A., The substantia gelatinosa of the spinal cord. A critical review, Brain, 103 (1980) 717-772.

6 Coggeshall, R. E., Coulter, J. D. and Willis, W. D., Jr., Unmyelinated axons in the ventral roots of the cat lumbosacral enlargement, J. comp. Neurol., 153 (1974) 39-58. bers and may belong to the $\mathrm{A} \delta$ or C-fiber group. These findings are in good agreement with data reported from lumbosacral ventral roots of the cat where unmyelinated afferent axons have been demonstrated ${ }^{6,7}$.

The responsiveness to phoretically-applied amino acid transmitters was found to be similar to that described for other dorsal horn neurons in deeper layers in vivo (for review see ref. 27 ) and in adult 26 and neonatal in vitro preparations ${ }^{18,19}$. A consistent finding was that SG-neurons responded to DADL with an inhibition of their spontaneous, synaptically or chemically induced discharge. This action was antagonized by naloxone suggesting an action mediated via opiate receptors. Both histochemical (refs. 21 and 22 and citations therein) and the present electrophysiological data (see also ref. 27) favor a postsynaptic localization of these receptors on cells in lamina 2. Intrathecal applications of opiates, therefore, may affect both projecting and intrinsic neurons in a common fashion and behavioral testing might reveal the net effect of this interaction. In the present study the site of action and the potential shifts in these neurons following opioids can only be indirectly assessed. Investigations employing intracellular recording techniques are in progress to analyze the ionic mechanisms underlying these actions in more detail.

The authors are grateful to Professor A. Herz for critically reading the manuscript, to $\mathrm{B}$. Bieletzki for technical assistance and to $S$. Zieglgänsberger for editing the manuscript.

7 Coggeshall, R. E. and Ito, H., Sensory fibres in ventral roots L7 and S1 in the cat, J. Physiol. (Lond.), 267 (1977) 215-235.

8 Dhanjal, S. S. and Sears, T. A., An in vitro slice preparation of adult mammalian spinal cord, J. Physiol. (Lond.), 312 (1981) 12P.

9 Dhanjal, S. S. and Sears, T. A., Electrical activity of rat substantia gelatinosa Rolandi studied in vitro, J. Physiol. (Lond.), 312 (1981) 19P.

10 Dubuisson, D., Fitzgerald, M. and Wall, P. D., Ameboid receptive fields in laminae 1,2 and 3, Brain Research, 177 (1979) 376-378.

11 Fry, J. P., Herz, A. and Zieglgänsberger, W., A demonstration of naloxone-precipitated opiate withdrawal on single neurones in the morphine-tolerant/dependent rat brain, Brit. J. Pharmacol., 68 (1980) 585-592.

12 Hentall, I., A novel class of unit in the substantia gelatinosa of the spinal cat, Exp. Neurol., 57 (1977) 792-806. 
13 Hökfelt, T., Johansson, O., Ljungdahl, A., Lundberg, J. M., and Schultzberg, M., Peptidergic neurones, Nature (Lond.), 284 (1980) 515-521.

14 Hunt, S. P., Nagy, J. I. and Ninkovic, M., Peptides and the organization of the dorsal horn. In B. Sjölund and A. Björklund (Eds.), Brain Stem Control of Spinal Mechanisms, Elsevier Biomedical Press, Amsterdam, 1982, pp. 159-178.

15 Kumazawa, T. and Perl, E. R., Differential excitation of dorsal horn and substantia gelatinosa marginal neurons by primary afferent units with fine (A and C) fibers. In Y. Zotterman (Ed.), Sensory Functions of the skin in Primates, Pergamon Press, Oxford, 1976, pp. 67-89.

16 Kumazawa, T., and Perl, E. R., Excitation of marginal and substantia gelatinosa neurons in the primate spinal cord: indications of their place in dorsal horn functional organisation, J. comp. Neurol., 177 (1978) 417-434.

17 Light, A. R., Trevino, D. L. and Perl, E. R., Morphological features of functionally defined neurons in the marginal zone and substantia gelatinosa of the spinal dorsal horn, $J$. comp. Neurol., 186 (1979) 151-172.

18 Miletic, V. and Randic, M., Neonatal rat spinal cord slice preparation: postsynaptic effects of neuropeptides on dorsal horn neurons, Develop. Brain Res., 2 (1982) 432-438.

19 Murase, K., Nedeljkov, V. and Randic, M., The actions of neuropeptides on dorsal horn neurons in the rat spinal cord slice preparation: an intracellular study, Brain Research, 234 (1982) 170-176.

20 Price, D. D., Hayashi, H., Dubner, R. and Ruda, M. A.,
Functional relationships between neurons of marginal and substantia gelatinosa layers of primate dorsal horn, J. Neurophysiol., 42 (1979) 1590-1608.

21 Ruda, M. A., Opiates and Pain Pathways: Demonstration of Enkephalin Synapses on Dorsal Horn Projection Neurons, Science, 215 (1982) 1523-1525.

22 Sumal, K. K., Pickel, V. M., Miller, R. J. and Reis, D. J., Enkephalin-containing neurons in substantia gelatinosa of spinal trigeminal complex: ultrastructure and synaptic interaction with primary sensory afferents, Brain Research, 248 (1982) 223-236.

23 Wall, P. D., The gate control theory of pain mechanisms. A re-examination and re-statement, Brain, 101 (1978) 1-18.

24 Wall, P. D., Merrill, E. G. and Yaksh, T. L., Response of single units in Laminae 2 and 3 of cat spinal cord, Brain Research, 160 (1979) 245-260.

25 Williams, J. T., and Zieglgänsberger, W., Neurons in the frontal cortex of rat carry multiple opiate receptors, Brain Research, 226 (1981) 304-308.

26 Yoshimura, M. and Nishi, S., Intracellular recordings from lateral horn cells of the spinal cord in vitro, J. auton. Nerv. Syst., 6 (1982) 5-11.

27 Zieglgänsberger, W., Cellular actions of putative transmitters of descending systems. In B. Sjölund and A. Börklund (Eds.), Brain Stem Control of Spinal Mechanisms, Elsevier Biomedical Press, Amsterdam, 1982, pp. 451-472.

28 Zieglgänsberger, W. and Puil, E. A., Actions of glutamic acid on spinal neurons, Exp. Brain Res., 17 (1973) 35-49. 